\title{
Energy-using durables - why consumers refrain from economically optimal choices
}

\section{Renate Schubert* and Marcel Stadelmann}

ETH Zürich, Zürich, Switzerland

Edited by:

Tobias Brosch, University of Geneva, Switzerland

\section{Reviewed by:}

Kenneth Gillingham, Yale University, USA

Hannes Weigt, University of Basel, Switzerland

\section{*Correspondence:}

Renate Schubert, ETH Zürich, Clausiusstrasse 37, 8092 Zürich, Switzerland

e-mail: schubert@econ.gess.ethz.ch

\begin{abstract}
Sustainable development requires increasing the energy efficiency, decreasing the growth rates of energy demand, and decreasing the $\mathrm{CO}_{2}$ emissions. In many countries, households' energy consumption is responsible for a considerable share of total energy demand and $\mathrm{CO}_{2}$ emissions. Energy-using durables are essential in this context. Aiming at sustainability, private households should buy more energy-efficient durables and use them in a more efficient way. In principle, it might even be economically optimal to buy the more energy-efficient products, since they result in lower total costs over their lifetime thus resulting in a positive net present value (NPV). However, when observing private households' purchase decisions, they often do not correspond to the economic optimum, resulting in an "energy-efficiency gap." This paper investigates into the reasons for the persistence of such a gap between energy-efficient products that would be economically optimal - but from which consumers refrain - and less energy-efficient products that consumers actually own or buy although they entail larger life-cycle costs. Factors, which seem to deter private households from purchasing energy-efficient products with positive NPVs, are, for example, insufficient information, limited attention, or inertia. We will show how these and other factors hinder private households from identifying and realizing their economically optimal choices and how such barriers can be overcome. We will present how properly designed energy labels could help to overcome the information-related causes of inefficiently low energy-efficiency investments and provide some additional policy recommendations that could help reaching the aforementioned goal of a reduction of households' energy demand and $\mathrm{CO}_{2}$ emissions in an adequate way.
\end{abstract}

Keywords: energy-efficiency gap, sustainability, insufficient information, limited attention, uncertainty of energy savings, inertia, energy labels, behavioral economics

\section{INTRODUCTION}

According to the latest reports of IPCC (Intergovernmental Panel on Climate Change) the scientific evidence reveals that the probability for men-made global climate change is very high (IPCC, 2014). The reports show that more than half of the $\mathrm{CO}_{2}$ that is already stored in the atmosphere had been released during the last 40 years. The (future) negative consequences of global climate change can be described more and more precisely and the $\mathrm{CO}_{2}$ amount that can still be emitted until 2050 without endangering the $2^{\circ} \mathrm{C}$ goals has to be limited to a maximum of $750 \mathrm{Gt}$ worldwide. It also turns out that climate policy will not be for free but that, on the other hand, it seems feasible to save the planet. There will be reductions in growth rates, but overall, positive growth rates will persist. Hence, the conclusion from these reports is that we should act and that it is affordable to act. The sooner we act, the more affordable it will be.

There are recommendations on how to act to prevent dangerous climate change for all different levels, like, for instance, the aggregate level of country-wide policies or the micro level of individual households. In this paper, we are especially interested in measures adequate for a reduction of $\mathrm{CO}_{2}$ emissions in private households. The motivation behind is the fact that more than
$50 \%$ of total current $\mathrm{CO}_{2}$ emissions stem from private households (including mobility) (Wiki Bildungsserver, 2013; BAFU, 2014). Mobility, electricity consumption, as well as heating or cooling of buildings are the key areas in which $\mathrm{CO}_{2}$ is released. This at least holds for households in developed countries, which is the reason why we will focus on such countries. There are essentially two ways to decrease individual households $\mathrm{CO}_{2}$ emissions in these countries. One would be to reduce the number and intensity of $\mathrm{CO}_{2}$ emitting uses, the second one would be to make the single uses less energy-intensive and hence, given that most energy uses still have fossil components, less $\mathrm{CO}_{2}$-emitting. Since the first way just mentioned might be related to serious welfare losses, we will concentrate on the second way, i.e., on measures to increase the energy efficiency of different uses. Hereby, we will limit our analysis to energy-using durables, leaving the analysis of infrastructural components like heating or cooling systems to further papers. Energy-using durables are typically responsible for about $80 \%$ of a private household's energy demand and for about 15 $20 \%$ of their $\mathrm{CO}_{2}$ emissions (BAFU, 2014; CSR Academy, 2014; Energybrain, 2014; Euresa, 2011).

Looking at energy-using durables like washing machines, fridges, coffee machines, TVs, computers, etc., we observe that in 
most developed countries a variety of product types with differing degrees of energy efficiency and differing prices are available. Only in some countries and for some products, government regulation forbids the sale of less energy-efficient product types. Comparing purchase prices plus current electricity costs for different types of one and the same product over the product's lifetime, it turns out that, taking into account a specific discount rate, it might be economically optimal to buy the more energy-efficient products. As a rule, these products will be sold at higher purchase prices. However, the lower current electricity costs throughout the whole lifetime of the product may outweigh the higher purchase prices. In economic terms, the net present value (NPV) of the more energy-efficient appliances will be higher than the NPV of the less energy-efficient appliances. Private households should hence be interested in buying energy-efficient durables with a higher NPV. Yet, one observes empirically that this is often not the case (see section 2). Many private households do not buy the appliances that would seemingly be economically optimal for them. This of course raises the question of why this is the case, i.e., why private consumers behave in a seemingly non-rational way.

In the literature, this phenomenon is well-known under the label of the "energy-efficiency gap." This gap consists of the discrepancy between energy-efficient or technologically efficient products that would be economically optimal - but from which consumers refrain - and less energy-efficient products that consumers actually own or buy although they entail larger life-cycle costs. From a purely methodological point of view, identifying this gap is not an easy task and the existing studies are of only limited value, due to their often short-sighted assumptions about economic optimality and time discounting. The literature discusses possible reasons for this discrepancy, which we will present in section 2 .

In section 3, we will then have a closer look at causes that might be responsible for the economically non-optimal behavior of consumers when purchasing energy-using durables. Most of these causes are information-related in one way or the other. So, we will discuss insufficient information, limited attention and perception biases, the uncertainty bias, inertia and social network aspects and, finally, liquidity constraints. Based on this discussion of reasons for the existence of an energy-efficiency gap, section 4 is then dedicated to possibilities of overcoming barriers to technologically and economically efficient household investments. Given the close relation of all principal causes to the aspect of information, we will focus on information format and disclosure types in this section. Energy labels, especially those for household appliances, will hence constitute the key example used in section 4 . Section 5 will be used for drawing conclusions on how to cope with the apparent discrepancy between alleged economic optimality and factual behavior of private households. We will end our paper with some policy recommendations that could help reaching the aforementioned goal of a reduction of households' energy demand and $\mathrm{CO}_{2}$ emissions in an adequate way.

\section{INSIGHTS FROM LITERATURE}

Since the early 1990s, a situation in which households' investments in energy-efficient appliances seem to be lower than privately optimal has been referred to as the energy-efficiency gap or energy-efficiency paradox (Hirst and Brown, 1990; Jaffe and Stavins, 1994). Investment also - or even more so - seems to be lower than socially optimal, but it is the private sub-optimality of investment that legitimates the term "paradox" from an economic perspective (see Jaffe et al., 2004 for a discussion of different optima related to energy efficiency). The suggested lack of investment in energy efficiency leads to a gap between actual and optimal energy use (Jaffe and Stavins, 1994). The paradox lies in the slow diffusion of apparently cost-effective and energy-efficient technologies (Shama, 1983). Many households seem to ignore the opportunities of positive NPV investments in high-efficiency durables judged by a reasonable market interest rate to calculate the present value of cost savings (Howarth and Stanstad, 1995). They either delay the replacement of low-efficiency products or settle for a low-efficiency product when purchasing an energy-using durable.

The energy-efficiency gap has become an increasingly popular topic in policy discussions because its reduction promises "win-win" opportunities. First, it allows reducing the negative externalities involved in current energy use, such as climate change, nuclear disasters, or dependencies on fuel imports. Switzerland, for example, imports $66 \%$ of its energy used, mostly in the form of fossil fuels, with major consequences for the environment, foreign policy, and the economy (Pomper, 2014). Second, other forces such as imperfect information may cause households not to undertake privately profitable investments in energy efficiency (Allcott and Greenstone, 2012). These forces present investment inefficiencies that lead to the "[...] Energy Efficiency Gap: a wedge between the cost-minimizing level of energy efficiency and the level actually realized" (Allcott and Greenstone, 2012, p. 4). Establishing the existence of an energy-efficiency gap would therefore justify largescale policy intervention targeted at closing the gap. In order to select the right tools for possible policy interventions, it is essential to identify the potential cause(s) of an energy-efficiency gap - an issue addressed in this article. In fact, many public policies have already been implemented to stimulate energy efficiency, leading to an extensive literature on energy efficiency and conservation policy evaluation (for reviews of this literature, see, e.g., Gillingham et al., 2006; Tietenberg, 2009; Abrahamse et al., 2005).

Several studies by McKinsey \& Company (Creyts et al., 2007; Granade et al., 2009; McKinsey \& Company, 2009a) and others (see, for example, Chandler and Brown, 2009; EPRI, 2009; National Academy of Sciences, 2009; Rosenfeld et al., 1993 for a meta-analysis of earlier studies) suggest that certain investments in energy efficiency could indeed result in net monetary savings for households and thus improve economic efficiency. In these cases, the present discounted value of future energy savings would exceed the upfront costs of investments in energy-efficient equipment and appliances at current energy costs and thus have a positive NPV. Hence, such investments would not only help to reduce energy demand, thanks to their technological efficiency, but would also be economically efficient.

In their study about the energy-efficiency potential in the U.S. economy, Granade et al. (2009) in their base case apply a 7\% discount rate as the cost of capital, use industrial retail rates as a proxy for the value of energy savings, and assume a zero price of carbon. Under these assumptions and for the current state of technology, they identify an energy saving potential of $\$ 1.2$ trillion at an 
upfront cost of $\$ 520$ billion (not including program costs) through 2020, pointing toward a potentially large energy-efficiency gap in the U.S. economy. There have been a limited number of such studies trying to estimate the economic potential of energy efficiency in Switzerland (see, e.g., McKinsey \& Company, 2009b; Infras \& TNC Consulting, 2010; McKinsey \& Company, 2010; BFE, 2007). Infras \& TNC Consulting (2010) provide an NPV estimate of CHF 7.6 billion until the year 2035 for energy-efficiency investments that would also be economically efficient. Hereby, they assume a constant interest rate of $2.5 \%$ and electricity prices increasing by $4 \%$ per 5-year period. However, such engineering estimates of the energy savings potential from seemingly cost-effective investments suffer from two major flaws: (1) the large sensitivity to the respective assumptions, such as the assumed discount rates or energy prices, and (2) the insufficient consideration of the household's perspective in the energy-efficiency investment decision (Gillingham and Palmer, 2014). Hence, in order to assess the economics of energy-efficiency investments, it is necessary to analyze consumer choices. This will be done in the following.

Attempts to empirically trace the existence of inefficient investment in energy efficiency in consumer choices date back to the 1970 s and 1980s, when a considerable number of studies estimated the discount rates implicit in actual purchase decisions of energyusing durables. The rate of time discounting implicitly applied by a consumer who is indifferent between some smaller earlier payment and some larger later payment is called the "implicit discount rate." Epper et al. (2011) provide a simple stylized example of the method to estimate implicit discount rates (p. 2): suppose a consumer is indifferent between two products, a high-efficiency product $H$ with a purchase price $p_{\mathrm{H}}$ and running costs $c_{\mathrm{H}}$, all accruing in $t=1$, and a low-efficiency product $L$ with price $p_{\mathrm{L}}$ and running costs $c_{\mathrm{L}}$ with $p_{\mathrm{H}}>p_{\mathrm{L}}$ and $c_{\mathrm{H}}<c_{\mathrm{L}}$. Assuming linear utility and equating the present value of total costs $p_{\mathrm{H}}+c_{\mathrm{H}} \exp (-\vartheta)$, yields an implicit discount rate of $\vartheta=-\ln \frac{p_{\mathrm{H}}-p_{\mathrm{L}}}{c_{\mathrm{L}}-c_{\mathrm{H}}}$.

Table 1 summarizes the estimates of product-specific implicit discount rates until 2010 (as presented in Epper et al., 2011, p. 2).

DEFRA (2010) observes that (p. 15):

- there is a wide range of discount rates, from 2 to $300 \%$, both within and across categories;

- most of the discount rates are considerably higher than market interest rates;

- discount rates are lower when saving energy is the primary purpose of the investment.

Table 1 | Estimated product-specific implicit discount rates p.a.

\section{Category}

Thermal insulation

Space heating

Air conditioning

Refrigerators

Lighting

Automobiles

Sources: Train (1985); DEFRA (2010).
Ever since the seminal publication by Hausman (1979), the second observation has been connected to attempts of quantifying an energy-efficiency gap. The difference between the implicit discount rates (see Table 1) and market interest rates (for example, the $2.5 \%$ used by Infras \& TNC Consulting, 2010), which we call the "discounting gap," often proves to be large. Hence, households are not willing to undertake energy saving investments with positive NPV, based on a current market interest rate for present value calculations. Discount rates in the range of 39-300\%, as estimated, for example, for the purchase of refrigerators, imply that households might massively undervalue future energy savings as opposed to the initial purchase price. This would lead to a slower diffusion of energy-efficient refrigerators than could be expected if households realized all positive-NPV investments (Gillingham and Palmer, 2014). Therefore, the presence of a discounting gap has commonly been ascribed to irrational purchase decisions by households - and thus as proof of an energy-efficiency gap.

However, this inference is premature. In order to value the rationality of households' purchase decisions, the market interest rate used to assess the discounting gap needs to be adjusted for the uncertainty about the future benefits of the energy-efficiency investment, which will be discussed in the next section. Additionally, the implicit discount rates estimated in most discrete choice models are a mix of households' rates of time preferences and other factors that make it seem as if they were part of the time preferences, as, for example, unobserved utility components. Along these lines, Jaffe et al. (2004) challenge the appropriateness of implicit discount rates estimated in energy-conservation investment decisions to prove the existence of an energy-efficiency gap (p. 87):

To observe that implicit discount rates are high, however, says nothing about the reason people make the decisions they make. One possibility is that people are applying normal discount rates in the context of significant market failures; another possibility is that people actually utilize high discount rates in evaluating future energy savings. [...] Thus, high implicit discount rates, on their own, are neither a market failure nor an explanation of observed behavior.

While the size of the energy-efficiency gap might thus have commonly been overestimated, there are several market failures and systematic behavioral biases in consumer decision making that suggest that the gap is real. These explanations of an energy-efficiency gap are elaborated in the following section.

\section{WHY DO CONSUMERS REFRAIN FROM ECONOMICALLY OPTIMAL CHOICES? BARRIERS TO ECONOMICALLY RATIONAL BEHAVIOR}

In this section, we will analyze in detail some of the reasons that could explain the existence of the so-called energy-efficiency gap. Hereby we assume that there are energy-using durables on the market, which are highly energy efficient and which, at the same time, are preferable from an economic point of view. If, under such circumstances, households do not buy the technologically and economically better appliances, something must prevent them from making choices, which are in their best interest. These barriers will now be looked at in detail. 


\subsection{INSUFFICIENT INFORMATION}

The first interesting barrier to economically rational decisions of private households on energy-using durables is insufficient information or knowledge. Many decision makers know very little about the short-term and, in particular, the long-term economic consequences of using a specific type of an energy-using durable. At the same time, possibilities to gather such information exist and this information is often not even costly, which limits the contention that decision makers might rationally be inattentive or informed incompletely (see, e.g., Gabaix, 2014; Sallee, 2014 for models of rational inattention). These possibilities are, however, rarely used - due, in part, to some general inertia in decision making, which will be discussed in more detail later in subsection 3.4 (Loewenstein et al., 2001; Weber, 2006). Another reason for refraining from collecting the information that would be necessary in order to make decisions, which are in one's own best interest, is the fact that in most countries, the sums at stake are rather small. Given the low electricity prices, the monetary savings achievable through technologically and economically efficient appliances are not decisive for most households. Hence, the incentives for collecting additional information are rather low. Furthermore, even the societal advantage of buying more energy-efficient durables and making a contribution to the mitigation of climate change seems not to incentivize decision makers for compiling more information to compare the different types of a specific product like, for instance, a fridge. The negative consequences of global warming appear very distant to many people, in terms of geography as well as in terms of time; the issues seem to be intangible and unimaginable and hence unimportant for many decision makers (Leiserowitz et al., 2006; Lorenzoni and Pidgeon, 2006; Leiserowitz, 2007; Lorenzoni et al., 2007).

Yet, one could argue that private households should not actively search for information but should be provided - and in fact are provided - with the relevant information by suppliers, agencies, utilities, etc. However, much of the available information is accessible from or distributed through channels that are not practical or not relevant for many actors. If the goal is to achieve a better level of information among the masses, a first step could consist in employing the same media that decision makers use in their daily lives. Nowadays, it appears that the most effective media are those with a network character, such as Facebook, Twitter, WhatsApp, etc. The main advantage of channeling information through these media is that they are highly frequented by actors for other purposes as well, so that the actors do not have to incur additional costs to gather information about the technological as well as economic advantages of energy-using durables. Although there seems to be a tendency that such channels become more and more important, there is still a lot of information available only in conventional forms, hereby reducing the likelihood to be taken into account.

A further aspect is the information format. It seems important to present the information in different ways to the various target groups. If a target group is addressed in a "suitable" manner, chances of their actual involvement with the topic rise substantially. Possible forms of presentation include texts or films, comics or games, newspaper articles or scientific publications, simple and concrete illustrations that the reader can easily relate to or more abstract ones, quantitative or qualitative illustrations, and so on. An illustrative example of the expanding range of conceivable methods of communicating and informing are websites that calculate individuals' ecological footprint (Wackernagel and Beyers, 2010). They allow website visitors to see what multiple of Earth's resources would be necessary in order to sustain an entire world population using resources to the same extent as they do themselves. This could make decision makers aware of the importance of making decisions which at the same time are advantageous for themselves and for the society as a whole, hence combining technological and economic efficiency when buying appliances. Further examples include mobile applications that compute the $\mathrm{CO}_{2}$ emissions associated with a shopping list or the presentation of the content of a scientific publication in the form of a graphic novel (Hamann et al., 2013). Depending on the relevant target group (children or adults, students or working population, men or women, etc.), the presentation of the information should be conceptualized differently in order to turn purchase decisions into well informed decisions, paving the way to individual and societal optimality.

The insufficient knowledge of many actors also manifests itself in the fact that they are not aware of their current energy costs and are not able to mentally categorize potential savings in this area (Thaler, 1985). Moreover, many actors are not even aware of how they could adapt their lifestyle in order to behave in a more sustainable, i.e., for example, more energy-efficient way (Gardner and Stern, 2008; Larrick and Soll, 2008; Attari et al., 2010). In other words, many decision makers have no correct ideas about which of their uses is related to a higher or a lower level of energy demand or to a higher or lower amount of monetary expenses.

Most actors are cognitively unable to perform cost-benefit analyses or to calculate option values, i.e., the value of future courses of action. These skills in turn would be necessary for making economically rational decisions. Furthermore, it is also worth noting that actors often refrain from informing themselves at all because they fear uncomfortable or negative components of this information, and tend to try to avoid this type of information (Cerulo, 2006; Norgaard, 2006). In a similar manner, actions with possible negative consequences are often avoided, even if the total potential benefits of an action would exceed its total potential costs (Bostrom et al., 2012).

Overall, the adequacy and accessibility of information seem to play an important role. At the same time, the cognitive and emotional skills of many private decision makers seem not sufficiently trained in order to search for and deal with the relevant information. Providing suitable information poses a challenge to scientists as well as firms and government institutions. One step toward this end may be, for example, to reduce the number of labels indicating environmental and energy-related effects of the consumption of specific goods. An additional step would be to also limit the amount of information which each of the remaining labels convey. A reduction of information to a comprehensible and manageable amount would matter. More details concerning ways to overcome information-related barriers for purchasing technologically and economically efficient household appliances will be discussed in section 4 of this paper. 
Besides the information provision, decision makers' capabilities to search and process relevant information would have to be strengthened. As already mentioned, this must comprise cognitive as well as emotional aspects. Improvements in environmentrelated education could be one element in this context.

If the already existing information can successfully be made accessible and understandable and thus be used more in actors' decision making, this could help both to eliminate uncertainties and to improve the information's credibility. In addition, if more convincing examples of a strong long-run orientation of actors could be perceived throughout society, a closing of the energyefficiency gap could be reached more easily. This is due to the fact that adapting to a behavior that is "common" in society is typically more attractive than swimming against the stream (for more details, see subsection 3.4).

\subsection{LIMITED ATTENTION AND PERCEPTION BIASES}

Since Simon (1955), who proposed a model of bounded rationality, it has been suggested that individuals simplify complex decisions, for example, by processing only a subset of information. Gabaix and Laibson (2006) analyze pricing with boundedly rational consumers who do not pay attention to hidden features of product prices, which they refer to as "add-on" costs. This finding is supported by recent empirical evidence that people are inattentive to ancillary product costs such as sales taxes (Chetty et al., 2009), shipping and handling charges (Hossain and Morgan, 2006), or out-of-pocket insurance costs (Abaluck and Gruber, 2011).

DellaVigna (2009) presents a simple model of attention as a scarce resource (p. 349):

Consider a good whose value V (inclusive of price) is determined by the sum of two components, a visible component $\mathrm{v}$ and an opaque component $\mathrm{o}, \mathrm{V}=\mathrm{v}+\mathrm{o}$. Due to inattention,

the consumer perceives the value to be $\widehat{\mathrm{V}}=\mathrm{v}+(1-\theta) o$, where $\theta$ denotes the degree of inattention, with $\theta=0$ as the standard case of full attention. The interpretation of $\theta$ is that each individual sees the opaque information o, but then processes it only partially, to the degree $\theta$. The inattention parameter $\theta$ is itself a function of the salience $s \in[0,1]$ of $o$ and of the number of competing stimuli $\mathrm{N}: \theta=\theta(\mathrm{s}, \mathrm{N})$. Based on the psychology evidence, I assume that the inattention $\theta$ is decreasing in the salience $s$ and increasing in the competing stimuli $\mathrm{N}: \theta_{s}^{\prime}<0$ and $\theta_{N}^{\prime}>0$. Inattention is zero for a fully salient signal: $\theta(1, \mathrm{~N})=0$.

Hossain and Morgan (2006) examine eBay auctions where the bidding price of an item is more vivid than the shipping costs, as the shipping costs are not part of the bidding process and not listed in the item title. In order to assess the effect of ancillary costs, they compare a situation without shipping costs $\left(c_{\mathrm{LO}}\right)$ to a treatment condition where the shipping costs represent the bulk of total costs $\left(c_{\mathrm{HI}}\right)$. In terms of the model introduced above, $\mathrm{v}$ is the value of the item and $\mathrm{o}$ is defined as the negative shipping cost: $\mathrm{o}=-\mathrm{c}$. In treatment $c_{\mathrm{LO}}$, Hossain and Morgan (2006) auction CDs with a $\$ 4$ reserve price and no shipping cost, while in treatment $c_{\mathrm{HI}}$, they auction CDs with a $\$ 0.01$ reserve price and a $\$ 3.99$ shipping cost. The change in reserve price guarantees that the two auctions are equivalent for a fully attentive bidder. The average revenue raised in treatment $c_{\mathrm{HI}}$ is $\$ 1.79$ higher $(\$ 10.16$ vs. $\$ 8.37$ ) than in treatment $c_{\mathrm{LO}}$, and is higher for 9 out of $10 \mathrm{CDs}$. These estimates imply substantial inattention: $\hat{\theta}=\frac{1.79}{3.99}=0.45$. A second set of auctions with higher shipping costs $\left(c_{\mathrm{LO}}=\$ 2\right.$ and $\left.c_{\mathrm{HI}}=\$ 6\right)$, leads to a smaller increase of revenues in the high shipping cost condition (\$12.87 vs. $\$ 12.15)$, corresponding to an inattention parameter $\widehat{\theta}=\frac{0.72}{4}=0.18$. These results prove that consumers' attention to ancillary product costs is indeed limited, especially when the size of the ancillary costs is relatively small compared to the purchase price of the item.

In the context of energy-using durables, the "shrouded" attribute is the running energy cost while the initial purchase price is much more salient. When buying energy-using durables such as cars, air conditioners, and light bulbs, households might thus be more attentive to the purchase price than to the running energy costs, leading to a higher weight of the former in purchase decisions. As presented in the empirical example above, the inattention to the energy costs is especially pronounced if they are small compared to the purchase price, as is the case for household appliances like, for example, refrigerators or washing machines. Therefore, due to inattention, households are less likely to purchase the more energy-efficient product that commonly entails a higher purchase price and lower running energy costs. This effect has been widely suggested in the theoretical literature as a potentially important driver of an energy-efficiency gap (see, e.g., Blumstein et al., 1980; Anderson and Claxton, 1982; Jaffe and Stavins, 1994; Sanstad and Howarth, 1994; and many others).

Empirical evidence for limited attention in the context of energy-using durables is scarce, but it seems very likely that the effects observed in other contexts are applicable to energy-using durables, especially if the energy costs are low relative to the purchase price. In an artifactual, computer-based field experiment, Allcott and Taubinsky (2014) assess the effect of an information treatment on the purchase of compact fluorescent light bulbs (CFLs) as opposed to incandescent light bulbs. They find a positive effect of the information intervention on the purchase of the energy-efficient CFLs. They try to disentangle how much the information treatment affected choices through increased attention vs. updated beliefs. While the wide dispersion in beliefs does not allow for a clear picture, Allcott and Taubinsky (2014) suggest that both factors contribute to the treatment effect, thus maintaining that limited attention is relevant in keeping households from buying CFLs.

Other sources for decision makers' limited attention are different perception biases. Limited attention may be due to the fact that the relevance of energy efficiency is not present in decision makers' subjective experience (e.g., because of very low monetary expenses for electricity) or because this topic is not sufficiently addressed in the media (e.g., the consequences of continued usage of appliances with low energy efficiency are hardly described). In this context, one often speaks of the so-called "availability bias." This bias causes people to perceive especially strong information that they are already familiar with or information that is mentally available, while not (or hardly) perceiving other information. An effect is mentally available if an individual is able to readily and easily imagine or recall the effect. Some phenomena seem to stick 
especially well in an actor's memory, namely if the actor has witnessed them first-hand or has access to lively recounts of others (Jungermann et al., 2005, pp. 173). Examples of the availability bias involving environmental issues in general as well as climate change in particular include the 2007 floods in England or the film The Day After Tomorrow. Both of these instances led to a temporarily very high awareness for environmental threats. However, the shocking effect of such events or accounts diminishes after only a few months and usually entirely vanishes after around 1 year.

Some effects are also strongly perceived because decision makers infer causalities. If a hot summer is explained as a result of climate change, decision makers' perception of climate change is very strong. This effect is also known as the "representativeness heuristic," which owes its name to the idea that an underlying phenomenon (climate change) is deduced from an individual event (hot summer) that is seen as representative for a group of events (Jungermann et al., 2005, p. 170).

Furthermore, events contradicting theories and beliefs actors hold are perceived especially strongly as well. If a very cold winter occurs, this event does not seem to fit into the general theme of global warming; so decision makers take particular notice of it. According to the representativeness heuristic, a very cold winter may be interpreted as indicating the absence of global warming. Because this interpretation contradicts a nowadays commonly held opinion, the phenomenon receives special attention. Studies show that focusing on climate change as a driver of change in the observable natural environment of households increases the households' willingness to adapt their behavior toward more sustainable, e.g., more energy-efficient behavior (Alberini et al., 2013, p. 75).

\subsection{UNCERTAINTY BIAS}

Purchasing a more energy-efficient durable typically encompasses larger certain initial costs than a less efficient alternative while being related to lower but uncertain running energy costs over the lifetime of the product. A biased perception of the uncertainty about future framework conditions such as the price of energy or the amount of energy saved often leads decision makers to refrain from purchasing the more energy-efficient and economically rational alternatives (Hassett and Metcalf, 1993; Metcalf and Hassett, 1999). If it is uncertain, for example, what the prices for electricity will be over the next 5,10 , or 20 years, or if it is unclear which technological and social innovations will emerge in the areas of housing and private consumption in the next 5, 10, 20 , or 30 years, this can undermine investments targeting a more efficient use of energy. Purchase decisions which, for a given set of parameters, seem rational and economically efficient, might not be efficient under differing future conditions.

Greene (2011) presents a model that demonstrates how the perception of uncertainty can lead to a bias - the "uncertainty-loss aversion bias" (ULAB). Due to the uncertainty about the value of future energy savings, the range of possible net values of the investment might also embrace the loss domain compared to the current status quo. If potential losses weigh more heavily in an investment decision than potential gains - as loss aversion would suggest (see, e.g., Kahneman et al., 1991) - the possibility of a potential loss could prevent some consumers from making the investment (Greene, 2011). Uncertainty coupled with loss aversion thus contributes to a "status quo bias" because the disadvantages of change are weighted more heavily than its advantages or chances (Anderson, 2003; DEFRA, 2010). This effect could be highly relevant for explaining an energy-efficiency gap. If private households expect, for example, decreasing electricity prices or totally new types of household appliances for the future, they may be reluctant to buy more energy-efficient durables today, even if these products are technologically and economically efficient under current conditions.

Irrespective of their economic effectiveness, energy-efficient appliances may require behavioral changes when using them. Using energy-saving shower heads, for instance, changes the way in which people shower. Decision makers may face substantial uncertainties about possible future returns to their behavioral changes like reduced monetary costs, increased reputation, etc. As compared with such uncertain benefits, the costs of behavioral change may seem overly high; a behavioral change and hence the underlying purchase of an energy-using durable may be considered as too risky and may be avoided by a decision maker affected by the ULAB. It has been shown, for example, that house owners who are in principle considering a renovation of their house to increase its energy efficiency often end up refraining from such a renovation if they are unsure about the development of future energy prices (Alberini et al., 2013). In order to promote behavioral changes toward economically optimal and energy-efficient investments, better information and protection with respect to future (cost-) developments should be provided so that the private households' uncertainty can be reduced. Notably, information about future developments can often only be provided in terms of probabilities. Yet, many people have trouble understanding and working with the concept of probability. At least for younger generations, this highlights a clear educational task while it might also help to provide the probabilistic information in terms of a frequency format rather than a percentage format (Cosmides and Tooby, 1996).

Another aspect of insufficient knowledge and uncertainty stems from the uncertainty about the behavior of others. If private households do not know how other households in their surroundings or networks will act, they are often not willing to change their behavior in a way that may have (short-run) negative consequences for themselves. Such negative consequences could, for instance, be the higher immediate purchase prices of appliances. Irrespective of the economic efficiency, private households may refrain from buying technologically and economically efficient durables because they are afraid that they will be the only ones carrying the higher initial costs, while everyone else will benefit from their behavior, i.e., from their investment in energy-efficient products (Prisoners' Dilemma, Kerr, 1983). The willingness to proactively enter such a scenario is understandably low, but should in many cases be significantly higher to induce behavioral changes toward more energy-efficient investments. Only if many other decision makers were to change their behavior as well and buy more energyefficient products with high initial purchase costs and low lifetime current costs would there be a noticeable impact (Larrick and Soll, 2008). 


\subsection{INERTIA, SOCIAL NETWORKS, AND SOCIAL NORMS}

A further barrier to purchasing technologically and economically efficient household appliances lies in the inertia of decision makers or their aversion toward change, labeled the status quo bias above (Epstein, 1999). Many decision makers shun the costs associated with change, which is why they do not change their electricity supplier or tariff despite knowing better, forgo renovations of their houses and apartments to make them more energy-efficient, or do not buy new energy-using durables, which might be advantageous from an individual as well as from a societal point of view. Inertia also restrains people from replacing older, less energy-efficient appliances which are still functioning through new appliances with higher technological and economic efficiency. Inertia can in some cases be explained by the fact that people fear making decisions that they may regret later on; for example, if future energy prices turn out differently than was expected when making a decision (Zeelenberg et al., 2002).

Inertia or the avoidance of costs incurred through behavioral change appears to be especially large when the behavioral change is not accompanied by a social compensation, e.g., reputation in society or special appreciation in friend circles. In this context, therefore, social networks play an important role (Abrahamse and Steg, 2009). For one, decision makers can use these social networks to receive appreciation for their energy-efficiency efforts. In addition, they can use the social networks to convince themselves that they are not the only ones making an effort for energy efficiency. The exchange of specific tips and hints can possibly even make individual investment efforts more efficient and effective. Given the experience and insights of their friends, private households may be able to better understand that buying energyefficient appliances may not only be advantageous for the society as a whole but also for themselves, on an individual level, with respect to long-term economic profitability. The role of experts or scientists in such networks is ambiguous. On the one side, experts could prove to be conducive with respect to both, information about impacts related to various energy-using durables as well as experience related to prior purchase decisions. However, the presence of experts may also deteriorate the trust potential within the network. Empirical evidence on the respective importance of both effects is still missing.

Related to the social compensation through social networks is also the effect of role models. If individual decision makers see athletes, actors, business people, politicians, or other people, they look up to behave in a certain way, for example, drive smaller cars or purchase household appliances with high technological and economic efficiency, this will often induce an imitative effect. This imitative effect will be stronger the more knowledge about the role models' behavior and the more support for the imitative behavior stems from the individual's social network (Tsakas, 2012). Thus, private households might buy energy-efficient appliances with the hope of hereby attaining social status and appreciation (Bird and Smith, 2005; Griskevicius et al., 2010).

Social norms prevailing in groups relevant for the decision makers prove to be crucial to how efficiently they handle their energy consumption (Schultz et al., 2007; Handgraaf et al., 2013). When complying with social sustainability norms of the relevant group, private households may be rewarded by a so-called warm-glow effect (Andreoni, 1990, 1995), i.e., they might receive positive utility not only from the consumption of a private good like an electronic device but also from the contribution to a public good, e.g., climate change mitigation. This means that even if decision makers would not recognize the individual economic advantage, they could obtain when buying technologically and economically efficient appliances that they might decide for the purchase of an energy-efficient appliance due to the related public good contribution and the respective altruistic utility. Furthermore, in general, social conformity increases most individuals' utility whereas social disapproval typically generates disutility due to other individuals' negative reactions to one's own behavior (Masclet et al., 2003; Bicchieri, 2006). Hence, given the dependence of households' utility on complying with social norms, measures shaping such norms in favor of high energy efficiency to be "cool" and "a must" might result in closing the energy-efficiency gap.

The above mentioned inertia is, among others, a reason why decision makers are susceptible to nudges (Thaler and Sunstein, 2008). Today, in several countries, nudges are observable in various areas like, for instance, organ donation, pension savings schemes, or electricity tariffs (Elektrizitätswerk der Stadt Zürich, EWZ). For the context discussed here, the idea would be to present economically efficient appliances as default options in a choice architecture. Decision makers can opt out of this default option and explicitly choose a less sustainable alternative instead. Studies have shown, however, that due to the inertia of decision makers, opting out is rather rare. This suggests that defaults or nudges might be an interesting way to promote widespread sustainable behavior (Dinner et al., 2011; Allcott and Mullainathan, 2010). A successful example related to purchasing energy-efficient and long-term economically profitable products is the furnishing of new buildings in the US with energy-saving light bulbs by default (Dinner et al., 2011).

The nudge approach is occasionally criticized for being paternalistic and imposing on individuals what they should choose to do. Empirical studies suggest, however, that nudges may rather help individuals follow strategies that they prefer anyway. For example, the number of actual kidney donations differs substantially between Germany, where not donating is the default option, and Austria, where donating is the default option (Nationaler Ethikrat, 2007). It can be assumed that the actual willingness to donate a kidney is similar in both countries. A further notable advantage of the nudge approach is that it can be employed not only by the government but also by private firms, for instance, by suppliers of energy-using durables.

Nudges might be especially useful because they reduce the decision-making costs for private households. Decision makers often need to incur high costs to gather enough information for a behavior-altering decision (information is dispersed, sometimes paradoxical and incomplete, etc., see subsection 3.1), and many individuals thus avoid the process of seeking information. Instead, they decide from the onset to keep away from the cognitive effort associated with the gathering of information, and stick to their previous behavior (Iyengar et al., 2006; Fasolo et al., 2009; Alberini et al., 2013). Here, the status quo bias mentioned above also kicks in. Nudges can help in this situation precisely because they help individuals with a certain willingness to change their behavior 
to do so without having to perform a large cognitive or general prospecting effort.

Finally, another form of inertia manifests itself in the fact that individuals often increase their sustainable behavior with regard to some resources, but simultaneously reduce their sustainable behavior with regard to others. An explanation that might be relevant for the context of purchasing energy-using durables is the so-called moral licensing effect (Mazar and Zhong, 2010). The moral licensing effect describes a situation in which a private household overall behaves in a rather environmentally friendly way, for instance, by refraining from car-driving or traveling by plane. Then, these consumers may have the impression that they have invested enough effort into fostering sustainability and that there is no need to purchase energy-efficient appliances with high purchase prices. This may hold even in case of economically efficient appliances as long as the economic efficiency is not noticed (see, e.g., subsection 3.2).

It is possible that the moral licensing effect is based on the so-called single action bias (Weber, 1997). According to this bias, often only one single change of behavior is made, for example, the general switching off of the standby-mode, without any additional energy saving or efficiency-increasing behavioral changes. Decision makers often already achieve a clear conscience through one action, and further behavioral changes are no longer perceived as necessary. This effect is also closely related to the "finite pool of worry" effect (Weber, 2006), which states that the behavioral changes caused by concern about climate change or limited natural resources are not infinite. If one is especially concerned about one area (for example, about the $\mathrm{CO}_{2}$ emissions caused by flying), one tends to be less concerned about other areas (for example, about the energy efficiency of household appliances) and not to change one's behavior in these other areas.

The exchange in social networks can help abate these effects, for example, if it becomes clear that the other members of the social network make sustainability efforts in some areas without making downward adjustments elsewhere. The minimum level of sustainability individuals seek to achieve can be influenced by the respective norm in the individual's social network and can thus be moved up or down (Schultz et al., 2007; Kotchen and Moore, 2008; Baeriswyl et al., 2011).

\subsection{LIOUIDITY CONSTRAINTS}

A further important reason for the gap between the availability of technologically and economically efficient appliances und households' factual purchase decisions lies in households' liquidity constraints (Golove and Eto, 1996). Even if households might wish to purchase the economically efficient energy-using durable, they are often not able to afford these options financially. This issue mainly arises because most energy-efficient appliances are characterized by higher initial investment costs and lower operational costs than less energy-efficient appliances. The high upfront costs have to be financed, which can fail due to the lack of personal financial resources and a lack of willingness or opportunities to take on debt. It is also possible that households' liquidity constraints are not factual but only perceived due to a limited financial budget for household appliances. This separation of monetary funds into different mental accounts violates the fungibility virtue of money and thus represents a type of behavioral bias called "mental accounting" (Thaler, 1985).

Actual liquidity constraints and the perception of an unfavorable relationship between benefits and costs or risks of sustainable behavior are often closely linked. In economically rather limited situations, risks and costs of energy-efficient investments are often overestimated, while their benefits tend to be underestimated, especially if the decision makers have a rather short-term perspective. Additionally, a liquidity constrained decision maker is more likely to possess preferences for the present so that the likelihood of long-run oriented purchases of energy-using durables is low. If one is able to make information about the private and societal benefits of technologically and economically efficient appliances more accessible and more credible, this could contribute to more energy-efficiency investments in spite of liquidity constraints. The integration of such information into private households' social networks could make a significant contribution in this context.

Furthermore, new business models could help reduce the liquidity requirements of decisions in favor of energy-efficient and economically rational durables and thus make this barrier less important. For example, with energy providers charging a higher monthly fee for newly bought efficient household appliances over a longer period of time instead of charging a relatively high purchase price once, one would support individual "purchase" decisions that could close the energy-efficiency gap. Such models already exist, for instance, within the area of investments into heating or cooling systems for individual property houses (Schläfli, 2012). These business models could be promoted using policy instruments, as for example, tax rebates or exemptions. Such models would help low-income households to enlarge their portfolio of feasible purchases of energy-using durables and could result in more durables' purchases which at the same time foster individual economic well-being as well as societal (environmental) welfare.

\section{OVERCOMING THE BARRIERS: THE EXAMPLE OF ENERGY LABELS}

Since energy-using durables can be used over a relatively long period without being depleted, the respective purchase decisions are rather complex and cognitively demanding. They have a long time horizon, requiring estimates on running costs for several years into the future. Such decisions present a challenge for many households, which is why availability, perception, and processing of information play an important role. Allcott and Greenstone (2012) even state (p. 19): "Imperfect information is perhaps the most important form of investment inefficiency that could cause an Energy-Efficiency Gap." In this section, we thus focus on information problems to exemplify the policy implications of the energy-efficiency gap (for a broad discourse about policy responses to barriers to energy efficiency, see, e.g., Gillingham et al., 2009; Tietenberg, 2009; Gillingham and Palmer, 2014).

Allcott and Taubinsky (2014) always mention imperfect information in combination with limited attention (p. 3): "[...] we focus on imperfect information and inattention because results from other literatures suggested that these two distortions could be large, [...]." Any information intervention can serve both to eliminate imperfect information and to direct the attention of households toward subsets of information that they were 
previously inattentive to. Therefore, Allcott and Taubinsky (2014) state (p. 3): "It is thus not unreasonable to assume that our information treatment is what we call a pure nudge: it informs all previously uninformed consumers and draws full attention to energy costs, with no other effects." In their artifactual field experiment of light bulb purchases, Allcott and Taubinsky (2014) find that the information treatment reduces both imperfect information and inattention, and thus increases purchases of the more energy-efficient CFLs.

In real world, labels portray an established instrument for information disclosure. In the context of energy-using durables, energy labels are a policy instrument used in many countries. There are several, mostly hypothetical studies analyzing the effects of different energy label formats on households' purchase decisions. Rohling and Schubert (2013) provide a thorough review of the literature on energy labels for household appliances. They show that a variety of energy-efficiency labels exist around the globe. The aim of such labels is to influence consumers' purchase decisions for household appliances by making them more energy-efficient. The way in which these labels are designed differs significantly. While some labels display details of a product's energy consumption in physical units (kilowatt hours), other labels focus on monetary units (for instance US\$). Most energy labels currently applied globally accumulate a product's energy use over the period of 1 year, while the energy consumption for a single use or for the product's expected lifetime could be alternative information presentation formats. The way in which information is presented matters since it directly impacts consumers' purchase decision. Larrick and Soll (2008) show that labels may even enhance less energyefficient decisions if the presented information is not perceived properly (MPG Illusion).

As visualized in Figure 1, energy labels can be divided into two categories: endorsement labels and comparative labels (see Wiel and McMahon, 2005). Endorsement labels are essentially "sealof-approvals" that are applied only to the most energy-efficient models of a specific product class or to model meeting certain sustainability criteria. Most endorsement labels are voluntary.

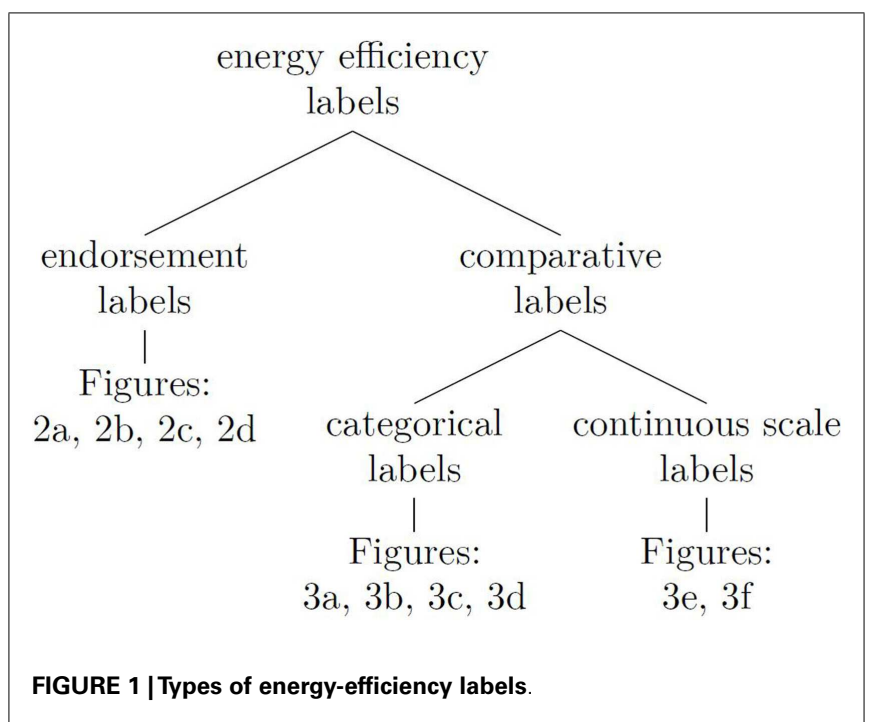

The probably best known endorsement label, the ENERGY STAR, was launched in 1992 in the US and is now also applied in many other countries such as most European countries, Canada, Australia, Japan, New Zealand, and Taiwan (see Figure 2A). The label identifies energy-efficient products in more than 40 categories, including major office equipment products, heating and cooling equipment, lighting, home electronics, buildings as well as plants. Other endorsement labels are, for example, the Chinese Energy-Conservation Certificate (see Figure 2B), the Recognitiontype Energy Label in Hong Kong (see Figure 2C), or the Highefficiency Appliance Certification in South Korea (see Figure 2D). Endorsement labels typically do not contain much information (Banerjee and Solomon, 2003). Since seal-of-approvals do not provide any product-specific information on energy consumption, no differentiation with respect to energy efficiency is possible among the labeled products.

Comparative labels, the second category of energy labels, provide a solid comparison of household appliances in terms of their energy efficiency. In most countries around the globe, comparative labels are mandatory: several household appliance categories are required to display such a label. Currently, labels follow two different approaches: labeling with categories (bar or dial/gage) and labeling with a continuous linear scale. In the first approach, products are put into different energy-efficiency categories. The labels allow a comparison of appliances across, but not within each energy-efficiency category. This approach is, for example, used for the EU Energy Label (see Figure 3A). From 1994 onward, retailers were required to display this label on new refrigerators, freezers, washing machines, and some other products like ovens or water heaters (European Parliament, 1992). The label originally had seven energy-efficiency categories A-G, with A being the best. In addition to the letter grades, energy-efficiency categories are visualized by bars of different color and length: green and short for $\mathrm{A}$, red and long for $\mathrm{G}$.

The energy-efficiency category that a product is assigned to is indicated by a black arrow located next to the colored bar. Since 2010, three new categories $\mathrm{A}+++, \mathrm{A}++$, and $\mathrm{A}+$ were added for refrigerating appliances, washing machines, and dish washers to respond to significant energy-efficiency improvements of these products (European Parliament, 2010). The design of the EU energy label is also used by several other countries, among them Switzerland, Brazil, Iran, Tunisia, and China (see Figure 3B).

Australia and similarly Japan, Thailand, South Korea, and India categorize electronic devices on a dial or gage (see Figures 3C,D). Depending on the product, five to seven stars rather than bars indicate a product's energy-efficiency category. A product's energy class is visualized by the number of stars that are highlighted in color, the more the better. In the second approach, a continuous linear scale displays the range of energy consumption between the most (left end of the scale) and least (right end of the scale) efficient appliance with similar product features. A product's relative performance is indicated by a small black arrow above the scale, the further left the better. Information on the product's energy use or energy costs, respectively, is attached to the black arrow. This format, which allows a direct comparison of energy consumption between appliances of even similar efficiency levels, is used for the US EnergyGuide and the Canadian EnerGuide (see Figures 3E,F). 
A

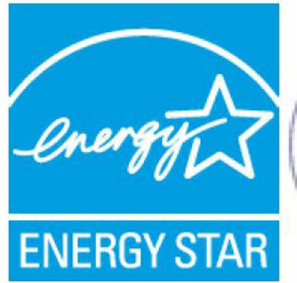

B

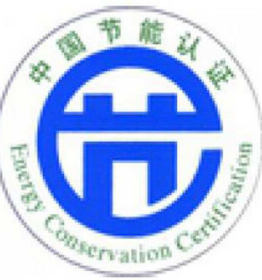

C

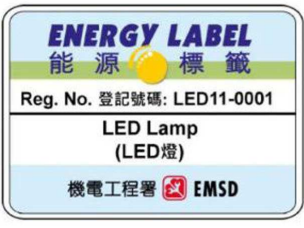

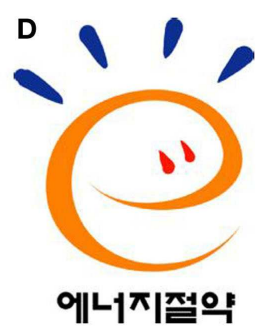

FIGURE 2 | Endorsement labels - (A): ENERGY STAR, (B): Chinese Energy-Conservation Program, (C): Recognition-type Energy Label, (D): South Korean High-efficiency Appliance Certification Program.

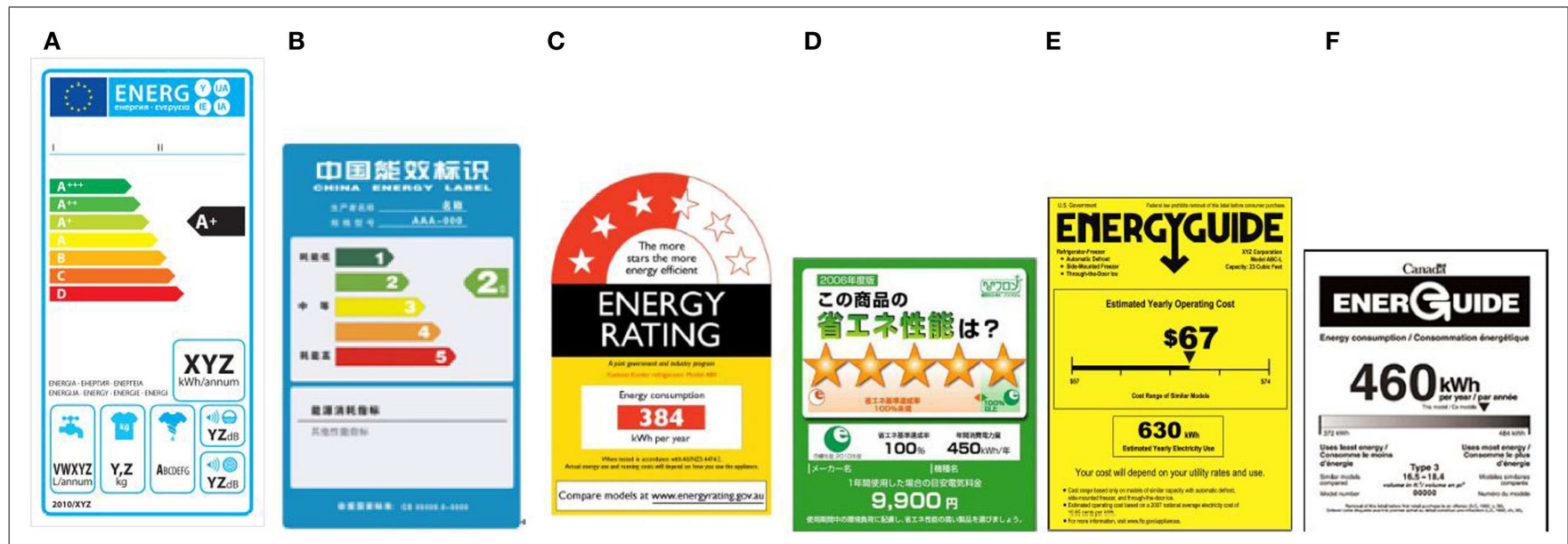

FIGURE 3 | Comparative labels - (A): EU Energy Label, (B): Chinese Energy Label, (C): Australian Energy Label, (D): Japanese Energy Label, (E): US EnergyGuide, (F): Canadian EnerGuide.

Currently, comparative labels not only differ with respect to their visualization of energy efficiency, i.e., categorical vs. continuous scale labels but also in their way of presenting information on energy consumption. The EU Energy Label, for example, provides several types of physical information, e.g., kilowatt hours/annum or water (in liters) per year. However, no information in monetary units is disclosed on this label. By contrast, the US EnergyGuide displays estimated yearly operating costs, i.e., monetary units, in the center of the label, while physical units are placed less prominently. The order of priority was reversed as part of a redesign of the label in 1994. However, since 2005 energy operating costs have again been placed in the center of the label. A new generation of labels has been introduced by the U.S. Environmental Protection Agency in 2011 for vehicles. It combines annual physical and monetary with an estimate of fuel costs over 5 years compared to the average new vehicle (EPA, 2011). The energy label used in Japan displays both economic and physical information, with yearly operating costs being placed more prominently. No unambiguous empirical evidence exists on whether monetary rather than physical units are advantageous for impacting customers' purchase decisions. Advantages of providing monetary figures are that money is a widely used unit with a clear meaning for consumers. Monetary indications may provide economic incentives to reduce energy consumption and hence to purchase more energyefficient appliances (McNeill and Wilkie, 1979). On the other hand, energy prices differ remarkably within the European Union or the US. Therefore, monetary units on the energy label might provide misleading information for consumers' purchase decisions.

Interestingly, irrespective of the fact whether monetary or physical units are displayed, all labels accumulate the respective information over the time period of 1 year. For specific product classes, like, for instance, washing machines, averaged annual data over several years may provide meaningful information. However, no label provides information on expected life-cycle energy consumption or costs. Since consumers typically perceive information as more important when a larger number is indicated (see, e.g., Camilleri and Larrick, 2014; Burson et al., 2009), presenting lifecycle information might strengthen the case for energy-efficient appliances. Yet, providing life-cycle information is no easy task and requires several assumptions, e.g., on product lifetime or discount rates, which may be contested.

In their literature review on empirically measured effects of different energy-efficiency label formats on consumers' purchase decisions, Rohling and Schubert (2013) find that energy labels might indeed impact households' purchases of energy-using durables. However, which label format is best for guiding 
households' choices toward more energy-efficient products remains disputable. Their synthesis shows that neither presenting energy use in monetary units nor in physical units was unambiguously relevant. Implications of presenting lifetime instead of annual information of a product's energy use were more consistent. The impact of labeling proved to be stronger when the information of energy use provided was accumulated over the product's expected lifetime. These effects, however, tend to be small and, at least in some studies, are not significant. Thus, while no unambiguous recommendation can be given as to whether monetary or physical units ought to be disclosed, lifetime information tends to have a stronger effect on energy-efficient purchases than monthly or yearly data.

On the other hand, it should be noted that the empirical evidence on the effect of the energy label on households' purchase decisions of energy-using durables is still rather sparse and dominated by hypothetical experiments and surveys. There are very few studies of actual purchase decisions, as for example, by Anderson and Claxton (1982) or Kallbekken et al. (2013). Additional studies on the effects of different energy label formats on households' purchase decisions of energy-using durables are thus desirable.

\section{CONCLUSION}

It turns out that there are several reasons why private households refrain from purchasing energy-efficient appliances even if it would be advantageous for them from an economic point of view. Hence, by providing economic incentives, private households' energy demand cannot be reduced as strongly as it would be possible if this energy-efficiency gap did not exist. Attempts to close the energy-efficiency gap would provide "win-win" opportunities: (1) private households could profit from lower running energy costs if they purchased economically efficient energy-using durables, and (2) societies on an aggregate level could mitigate climate change while moving toward more independent and secure energy systems.

It is thus highly relevant to identify the reasons for the persistence of the energy-efficiency gap in order to enable the design of targeted policy interventions. These reasons lie essentially in information-related problems like insufficient information, limited attention, and uncertainty bias as well as in psychological factors like inertia on the one hand and social networks and social norms on the other hand. The third relevant category consists in households' liquidity constraints, which might be factual or perceived constraints.

From a policy perspective, it seems most worthwhile to primarily tackle the information-related reasons for the persistence of the energy-efficiency gap. Such measures seem to be highly costefficient. One possibility is hence to promote and design energy labels in a way that helps to convey the information of economic optimality to households. Concerning the other factors hindering energy-efficient investments, liquidity constraints - especially the factual ones - could be overcome by exempting households in need from some of the investment costs that would have to be raised in order to purchase energy-efficient appliances. The psychological factors seem to be the most problematic when trying to close the energy-efficiency gap. They require a lot of refinement in choice architecture surrounding purchase decisions with respect to energy-using durables because factors like social norms cannot be easily set or altered by regulating agencies. It seems as if more research efforts would be needed in this area. On the other hand, one might suppose that already accepting the relevance of social norms and of social networks would bring some success. Innovation in the area of social networking is required. Some approaches like, for instance, using firms as catalytic for informing their employees about the economic optimality of more energyefficient appliances in their private homes, are already in sight and seem quite promising (Pan European Networks, 2014).

\section{REFERENCES}

Abaluck, J., and Gruber, J. (2011). Choice inconsistencies among the elderly: evidence from plan choice in the medicare part d program. Am. Econ. Rev. 101, 1180-1210. doi:10.1257/aer.101.4.1180

Abrahamse, W., and Steg, L. (2009). How do socio-demographic and psychological factors relate to households' direct and indirect energy use and savings? J. Econ. Psychol. 30, 711-720. doi:10.1016/j.joep.2009.05.006

Abrahamse, W., Steg, L., Vlex, C., and Rothengatter, T. (2005). A review of intervention studies aimed at household energy conservation. J. Environ. Psychol. 25, 273-291. doi:10.1016/j.jenvp.2005.08.002

Alberini, A., Banfi, S., and Ramseier, C. (2013). Energy efficiency investments in the home: Swiss homeowners and expectations about future energy prices. Energy J. 34, 49-86. doi:10.5547/01956574.34.1.3

Allcott, H., and Greenstone, M. (2012). Is there an energy efficiency gap? J. Econ. Perspect. 26, 3-28. doi:10.1257/jep.26.1.3

Allcott, H., and Mullainathan, S. (2010). Behavior and energy policy. Science 327, 1204-1205. doi:10.1126/science.1180775

Allcott, H., and Taubinsky, D. (2014). The lightbulb paradox: using behavioral economics for policy evaluation. NBER Working Paper (19713), Cambridge, MA.

Anderson, C. D., and Claxton, J. D. (1982). Barriers to consumer choice of energyefficient products. J. Consum. Res. 9, 163-170. doi:10.1086/208909

Anderson, C. J. (2003). The psychology of doing nothing: forms of decision avoidance result from reason and emotion. Psychol. Bull. 129, 139-167. doi:10.1037/ 0033-2909.129.1.139

Andreoni, J. (1990). Impure altruism and donations to public goods: a theory of warm-glow giving? Econ. J. 100, 464-477. doi:10.2307/2234133

Andreoni, J. (1995). Warm-glow versus cold-prickle: the effects of positive and negative framing on cooperation in experiments. Q. J. Econ. 110, 1-21. doi:10.2307/ 2118508

Attari, S. Z., DeKay, M. L., Davidson, C. I., and de Bruin, W. B. (2010). Public perceptions of energy consumption and savings. Proc. Natl. Acad. Sci. U.S.A. 107, 16054-16059. doi:10.1073/pnas.1001509107

Baeriswyl, M., Staake, T., and Loock, C.-M. (2011). "The effects of user identity and sanctions in online communities on real-world behavior," in ICIS 2011 Proceedings, 12. Available at: http://aisel.aisnet.org/icis2011/proceedings/ onlinecommunity/12

BAFU. (2014). Entwicklung der Treibhausgasemissionen in den einzelnen Sektoren. Available at: http://www.news.admin.ch/NSBSubscriber/message/attachments/ 34423.pdf

Banerjee, A., and Solomon, B. D. (2003). Ecolabeling for energy efficiency and sustainability: a meta-evaluation of US programs. Energy Policy 31, 109-123. doi:10.1016/S0301-4215(02)00012-5

BFE. (2007). Die Energieperspektiven 2035. Available at: http://www.bfe.admin.ch/ themen/00526/00538/index.html?lang=de

Bicchieri, C. (2006). The Grammar of Society: The Nature and Dynamics of Social Norms. Cambridge: Cambridge University Press.

Bird, R. B., and Smith, E. A. (2005). Signaling theory, strategic interaction, and symbolic capital. Curr. Anthropol. 46, 221-248. doi:10.1086/427115

Blumstein, C., Krieg, B., Schipper, L., and York, C. (1980). Overcoming social and institutional barriers to energy conservation. Energy 5, 355-371. doi:10.1016/ 0360-5442(80)90036-5

Bostrom, A., O’Connor, R. E., Böhm, G., Hanss, D., Bodi, O., Ekström, F., et al. (2012). Causal thinking and support for climate change policies: international survey findings. Glob. Environ. Change 22, 210-222. doi:10.1016/j.gloenvcha. 2011.09.012 
Burson, K., Larrick, R., and Lynch, J. J. (2009). Six of one, half dozen of the other: expanding and contracting numerical dimensions produces preference reversals. Psychol. Sci. 20, 1074-1078. doi:10.1111/j.1467-9280.2009.02394.x

Camilleri, A. R., and Larrick, R. P. (2014). Metric and scale design as choice architecture tools. J. Public Policy Mark. 33, 108-125. doi:10.1509/jppm.12.151

Cerulo, K. (2006). Never Saw It Coming: Cultural Challenges to Envisioning the Worst. Chicago, IL: University of Chicago Press.

Chandler, S. J., and Brown, M. A. (2009). Meta-review of efficiency potential studies and their implications for the south. Working Paper, 51. Atlanta, GA: Georgia Tech Ivan College of Public Policy.

Chetty, R., Looney, A., and Kroft, K. (2009). Salience and taxation: theory and evidence. Am. Econ. Rev. 99, 1145-1177. doi:10.1257/aer.99.4.1145

Cosmides, L., and Tooby, J. (1996). Are humans good intuitive statisticians after all? Rethinking some conclusions of the literature on judgment under uncertainty. Cognition 58, 1-73. doi:10.1016/0010-0277(95)00664-8

Creyts, J., Derkach, A., Nyquist, S., Ostrowski, K., and Stephenson, J. (2007). Reducing U.S. Greenhouse Gas Emissions: How Much at What Cost? Chicago, IL: McKinsey \& Company.

CSR Academy. (2014). Reducing Carbon Emissions in Everyday Life, eds N. SchuldtBaumgart and E. Stiess. Available at: http://csr-manager.org/en/agenda/Dossiers/ Climate-Change/Reducing-Carbon-Emissions-in-Everyday-Life.php

DEFRA. (2010). Behavioural Economics and Energy-Using Products: Scoping Research on Discounting Behaviour and Consumer Reference Points. DEFRA Research Report. London: DEFRA.

DellaVigna, S. (2009). Psychology and economics: evidence from the field. J. Econ. Lit. 47, 315-372. doi:10.1257/jel.47.2.315

Dinner, I., Johnson, E. J., Goldstein, D. G., and Liu, K. (2011). Partitioning default effects, why people choose not to choose. J. Exp. Psychol. Appl. 17, 332-341. doi: $10.1037 / \mathrm{a} 0024354$

Energybrain. (2014). Stromverbrauch in Schweizer Haushalten. Available at: http: //energybrain.ch/konsumentinnen/konsumentinnen.asp

EPA. (2011). A New Fuel Economy Label for a New Generation of Cars. Available at: http://www.fueleconomy.gov/feg/label/docs/EPA_FE_Label-052311.pdf

Epper, T., Fehr-Duda, H., and Schubert, R. (2011). Energy-using durables: the role of time discounting in investment decisions, IED Working Paper, 16. Zürich: ETH Zürich.

EPRI. (2009). Assessment of Achievable Potential from Energy Efficiency and Demand Response Programs in the US 2010-2030. Palo Alto, CA: Electric Power Research Institute.

Epstein, L. G. (1999). A definition of uncertainty aversion. Rev. Econ. Stud. 66, 579-608. doi:10.1111/1467-937X.00099

Euresa. (2011). Causes of $\mathrm{CO}_{2}$ in the Households. Available at: http://www.euresa. org/index.php?id=1140\&L=1

European Parliament. (1992). Council Directive 92/75/EEC. Official Journal of the European Union. L 297, 35, 16-20.

European Parliament. (2010). Directive 2010/30/EU of the European Parliament and of the Council. Official Journal of the European Union. L 153, 53, 1-12.

Elektrizitätswerk der Stadt Zürich (EWZ). (2007). Ökologisch! Oder konventionell? Die Wahl Ihres persönlichen Stromprodukts hat viel bewirkt, Broschüre zur Tarifumstellung. Zürich: EWZ.

Fasolo, B., Carmeci, F. A., and Misuraca, R. (2009). The effect of choice complexity on perception of time spent choosing: when choice takes longer but feels shorter. Psychol. Mark. 26, 213-228. doi:10.1002/mar.20270

Gabaix, X. (2014). A sparsity-based model of bounded rationality. Q. J. Econ. 129, 1661-1710. doi:10.1093/qje/qju024

Gabaix, X., and Laibson, D. (2006). Shrouded attributes, consumer myopia, and information suppression in competitive markets. Q. J. Econ. 121, 505-540. doi:10.1162/qjec.2006.121.2.505

Gardner, G. T., and Stern, P. C. (2008). The short list - the most effective actions US households can take to curb climate change. Environment 50, 12-24. doi:10.3200/ENVT.50.5.12-25

Gillingham, K., Newell, R. G., and Palmer, K. (2006). Energy efficiency policies: a retrospective examination. Annu. Rev. Environ. Resour. 31, 161-192. doi:10.1146/annurev.energy.31.020105.100157

Gillingham, K., Newell, R. G., and Palmer, K. (2009). Energy efficiency economics and policy. Discussion Paper. Washington, DC.

Gillingham, K., and Palmer, K. (2014). Bridging the energy efficiency gap: policy insights from economic theory and empirical evidence. Rev. Environ. Econ. Policy 8, 18-38. doi:10.1093/reep/ret021
Golove, W. H, and Eto, J. H. (1996). Market Barriers to Energy Efficiency: A Critical Reappraisal of the Rationale for Public Policies to Promote Energy Efficiency, LBL-38059. Berkeley, CA: Lawrence Berkeley National Laboratory.

Granade, H. C., Creyts, J., Derkach, A., Farese, P., Nyquist, S., and Ostrowski, K. (2009). Unlocking Energy Efficiency in the U.S. Economy. Stamford, CT: McKinsey \& Company.

Greene, D. L. (2011). Uncertainty, loss aversion, and markets for energy efficiency. Energy Econ. 33, 608-616. doi:10.1016/j.eneco.2010.08.009

Griskevicius, V., Tybur, J. M., and Van den Bergh, B. (2010). Going green to be seen: status, reputation, and conspicuous conservation. J. Pers. Soc. Psychol. 98, 392-404. doi:10.1037/a0017346

Hamann, A., Zea-Schmidt, C., and Leinfelder, R. (Hrsg.). (2013). Die große Transformation: Klima - Kriegen wir die Kurve? Berlin: Verlagshaus Jacoby \& Stuart.

Handgraaf, M. J. J., Van Lidth de Jeude, M. A., and Appelt, K. C. (2013). Public praise vs. private pay: effects of rewards on energy conservation in the workplace. Ecol. Econ. 86, 86-92. doi:10.1016/j.ecolecon.2012.11.008

Hassett, K. A., and Metcalf, G. E. (1993). Energy conservation investment. Energy Policy 21, 710-716. doi:10.1016/0301-4215(93)90294-P

Hausman, J. A. (1979). Individual discount rates and the purchase and utilization of energy-using durables. Bell J. Econ. 10, 33-54. doi:10.2307/3003318

Hirst, E., and Brown, M. (1990). Closing the efficiency gap: barriers to the efficient use of energy. Resourc. Conservat. Recycl.3,267-281. doi:10.1016/0921-3449(90) 90023-W

Hossain, T., and Morgan, J. (2006). ...Plus shipping and handling: revenue (non) equivalence in field experiments on eBay. B.E. J. Econ. Anal. Policy 5, 1-30. doi:10.2202/1538-0637.1429

Howarth, R. B., and Stanstad, A. H. (1995). Discount rates and energy efficiency. Contemp. Econ. Policy 13, 101-109. doi:10.1111/j.1465-7287.1995.tb00726.x

Infras \& TNC Consulting. (2010). Stromeffizienz und Erneuerbare Energien Wirtschaftliche Alternatie zu Grosskraftwerken. Zürich, CH: Infras/TNC.

IPCC. (2014). Climate change 2014: mitigation of climate change. Contribution of Working Group III to the Fifth Assessment Report of the Intergovernmental Panel on Climate Change, eds O. Edenhofer, R. Pichs-Madruga, Y. Sokona, E. Farahani, S. Kadner, K. Seyboth, et al. (Cambridge: Cambridge University Press).

Iyengar, S. S., Wells, R. E., and Schwartz, B. (2006). Doing better but feeling worse looking for the "best" job undermines satisfaction. Psychol. Sci. 17, 143-150. doi:10.1111/j.1467-9280.2006.01677.x

Jaffe, A. B., Newell, R. G., and Stavins, R. N. (2004). Economics of energy efficiency. Encycl. Energy 2, 79-90. doi:10.1016/B0-12-176480-X/00228-X

Jaffe, A. B., and Stavins, R. N. (1994). The energy-efficiency gap - what does it mean? Energy Policy 22, 804-810. doi:10.1016/0301-4215(94)90138-4

Jungermann, H., Pfister, H.-R., and Fischer, K. (2005). Die Psychologie der Entscheidung. Eine Einführung. 2. Aufl. München: Spektrum Akademischer Verlag.

Kallbekken, S., Saelen, H., and Hermansen, E. A. T. (2013). Bridging the energy efficiency gap: a field experiment on lifetime energy costs and household appliances. J. Consum. Policy 36, 1-16.

Kahneman, D., Knetsch, J. L., and Thaler, R. H. (1991). Anomalies: the endowment effect, loss aversion, and the status quo bias. J. Econ. Perspect. 5, 193-206. doi:10.1257/jep.5.1.193

Kerr, N. L. (1983). Motivation losses in small groups: a social dilemma analysis. J. Pers. Soc. Psychol. 45, 819-828. doi:10.1037/0022-3514.45.4.819

Kotchen, M. J., and Moore, M. R. (2008). Conservation: from voluntary restraint to a voluntary price premium. Environ. Resour. Econ. 40, 195-215. doi:10.1007/ s10640-007-9148-x

Larrick, R. P., and Soll, J. B. (2008). The MPG illusion. Science 320, 1593-1594. doi:10.1126/science.1154983

Leiserowitz, A. (2007). American Opinions on Global Warming. New Haven, CT: A Yale-Gallup-ClearVision Institute Poll, Yale School of Forestry and Environmental Studies.

Leiserowitz, A., Kates, R., and Parris, T. (2006). Sustainability values, attitudes, and behaviors: a review of multinational and global trends. Annu. Rev. Environ. Resour. 31, 413-444. doi:10.1146/annurev.energy.31.102505.133552

Loewenstein, G., Weber, E., Hsee, C., and Welch, E. (2001). Risk as feelings. Psychol. Bull. 127, 267-286. doi:10.1037/0033-2909.127.2.267

Lorenzoni, I., Nicholson-Cole, S., and Whitmarsh, L. (2007). Barriers perceived to engaging with climate change among the UK public and their policy implications. Glob. Environ. Change 17, 445-459. doi:10.1016/j.gloenvcha.2007. 01.004 
Lorenzoni, I., and Pidgeon, N. F. (2006). Public views on climate change: European and USA perspectives. Clim. Change 77, 73-95. doi:10.1007/s10584006-9072-z

Masclet, D., Noussair, C., Tucker, S., and Villeval, M.-C. (2003). Monetary and nonmonetary punishment in the voluntary contributions mechanism. Am. Econ Rev. 93, 366-380. doi:10.1257/000282803321455359

Mazar, N., and Zhong, C. B. (2010). Do green products make us better people? Psychol. Sci. 21, 494-498. doi:10.1177/0956797610363538

McKinsey \& Company. (2009a). Pathways to a Low-Carbon Economy: Version 2 of the Global Greenhouse Gas Abatement Curve. New York, NY: McKinsey \& Company.

McKinsey \& Company. (2009b). Swiss Greenhouse Gas Abatement Cost Curve. Zürich, CH: McKinsey \& Company.

McKinsey \& Company. (2010). Wettbewerbsfaktor Energie. Zürich, CH: McKinsey \& Company.

McNeill, D. L., and Wilkie, W. L. (1979). Public policy and consumer information: impact of the new energy labels. J. Consum. Res. 6, 1-11.

Metcalf, G. E., and Hassett, K. A. (1999). Measuring the energy savings from home improvement investments: evidence from monthly billing data. Rev. Econ. Stat. 81, 516-528. doi:10.1162/003465399558274

National Academy of Sciences. (2009). Real Prospects for Energy Efficiency in the U.S. Washington, DC: National Academies Press.

Nationaler Ethikrat. (2007). Die Zahl der Organspenden erhöhen - Zu einem drängenden Problem der Transplantationsmedizin in Deutschland. Berlin: Nationaler Ethikrat.

Norgaard, K. M. (2006). We don't really want to know: environmental justice and socially organized denial of global warming in Norway. Organ. Environ. 19 347-370. doi:10.1177/1086026606292571

Pan European Networks. (2014). “Taking the lead," in Pan European Networks: Government. 11, 58.

Pomper, D. (2014). “66 Prozent: Energie-Import entzweit die Gemüter,” in 20 Minuten. Issue from October 6. Zürich: Tamedia.

Rohling, M., and Schubert, R. (2013). Energy labels for household appliances and their disclosure format: a literature review. IED Working Paper, 21. Zürich: ETH Zürich.

Rosenfeld, A., Atkinson, C., Koomey, J., Meier, A., Mowris, R. J., and Price, L. (1993). Conserved energy supply curves for U.S. buildings. Contemp. Policy Issues 11, 45-68. doi:10.1111/j.1465-7287.1993.tb00370.x

Sallee, J. (2014). Rational inattention and energy efficiency. J. Law Econ. 57, 781-820. doi:10.1086/676964

Sanstad, A., and Howarth, R. (1994). 'Normal' markets, market imperfections, and energy efficiency. Energy Policy 22, 811-818. doi:10.1016/0301-4215(94) 90139-2

Schläfli, S. (2012). "Kraftwerk auf Anhänger," in Handelszeitung. 43, Issue from October 2012, 69 Zürich: Axel Springer Schweiz.

Schultz, P. W., Nolan, J. M., Cialdini, R. B., Goldstein, N. J., and Griskevicius, V. (2007). The constructive, deconstructive and reconstructive power of social norms. Psychol. Sci. 18, 429-434. doi:10.1111/j.1467-9280.2007.01917.x

Shama, A. (1983). Energy conservation in us buildings: solving the high potential/low adoption paradox from a behavioural perspective. Energy Policy 11, 148-167. doi:10.1016/0301-4215(83)90027-7
Simon, H. A. (1955). A behavioral model of rational choice. Q. J. Econ. 69, 99-118. doi: $10.2307 / 1884852$

Thaler, R. H. (1985). Mental accounting and consumer choice. Mark. Sci.4, 199-214. doi:10.1287/mksc.4.3.199

Thaler, R. H., and Sunstein, C. R. (2008). Nudge: Improving Decisions About Health, Wealth, and Happiness. New Haven, CT: Yale University Press, 2008.

Tietenberg, T. (2009). Reflections - energy efficiency policy: pipe dream or pipeline to the future? Rev. Environ. Econ. Policy 3, 304-320. doi:10.1093/reep/rep004

Train, K. (1985). Discount rates in consumers' energy-related decisions: a review of the literature. Energy 10, 1243-1253. doi:10.1016/0360-5442(85)90135-5

Tsakas, N. (2012). Naive learning in social networks: imitating the most successful neighbor. MPRA Paper 37796. Available at: http://mpra.ub.uni-muenchen.de/ $37796 /$

Wackernagel, M., and Beyers, B. (2010). Der Ecological Footprint. Die Welt neu vermessen. Hamburg: Europäische Verlagsanstalt.

Weber, E. U. (1997). "Perception and expectation of climate change: precondition for economic and technological adaptation," in Psychological and Ethical Perspectives to Environmental and Ethical Issues in Management, eds M. Bazerman, D. Messick, A. Tenbrunsel, and K. Wade-Benzoni (San Francisco, CA: Jossey-Bass), 314-341.

Weber, E. U. (2006). Experience-based and description-based perceptions of longterm risk: why global warming does not scare us (yet). Clim. Change 77, 103-120. doi:10.1007/s10584-006-9060-3

Wiel, S., and McMahon, J. (2005). Energy-Efficiency Labels and Standards: A Guidebook for Appliances, Equipment, and Lightning, 2 Edn. Washington, DC: Collaborative Labeling and Appliance Standards Program (CLASP).

Wiki Bildungsserver. (2013). $\mathrm{CO}_{2}$-Emissionen Durch Private Haushalte. Available at: http://wiki.bildungsserver.de/klimawandel/index.php/CO2-Emissionen durch_private_Haushalte

Zeelenberg, M., van den Bos, K., van Dijk, E., and Pieters, R. (2002). The interaction effect in the psychology of regret. J. Pers. Soc. Psychol. 82, 314-327. doi:10.1037/0022-3514.82.3.314

Conflict of Interest Statement: The authors declare that the research was conducted in the absence of any commercial or financial relationships that could be construed as a potential conflict of interest.

Received: 18 December 2014; accepted: 05 February 2015; published online: 23 February 2015 .

Citation: Schubert $R$ and Stadelmann $M$ (2015) Energy-using durables - why consumers refrain from economically optimal choices. Front. Energy Res. 3:7. doi: 10.3389/fenrg.2015.00007

This article was submitted to Energy Systems and Policy, a section of the journal Frontiers in Energy Research.

Copyright (C) 2015 Schubert and Stadelmann. This is an open-access article distributed under the terms of the Creative Commons Attribution License (CC BY). The use, distribution or reproduction in other forums is permitted, provided the original author(s) or licensor are credited and that the original publication in this journal is cited, in accordance with accepted academic practice. No use, distribution or reproduction is permitted which does not comply with these terms. 